

\title{
Emotional State and Market Behavior
}

\author{
Adriana Breaban \\ Universitat Jaume I \\ LEE \& Department of Economics \\ breaban@uji.es
}

\author{
Charles N. Noussair \\ Tilburg University \\ Department of Economics \\ C.N.Noussair@tilburguniversity.edu
}

\section{3 / 08}

\begin{abstract}
We consider the relationship between the emotional state of asset traders and market prices. We create experimental asset markets with the structure first studied by Smith, Suchanek and Williams (1988), which is known to generate price bubbles and crashes. We analyze participants' facial expressions with facereading software before and while the market is operating. We find that greater positive emotion in facial expressions before the market opens predicts higher prices and larger bubbles. Greater fear predicts lower prices and smaller bubbles. Those traders who remain the most neutral during periods of market volatility achieve the highest earnings. Loss aversion in decision making is correlated with fear, but not with other emotions.
\end{abstract}

Keywords: Bubble, Emotions, Facereading, Face, Crash

JEL classification: C92, G02 


\title{
Emotional State and Market Behavior
}

\author{
Adriana Breaban and Charles N. Noussair ${ }^{*}$
}

June 2013

\begin{abstract}
We consider the relationship between the emotional state of asset traders and market prices. We create experimental asset markets with the structure first studied by Smith, Suchanek and Williams (1988), which is known to generate price bubbles and crashes. We analyze participants' facial expressions with facereading software before and while the market is operating. We find that greater positive emotion in facial expressions before the market opens predicts higher prices and larger bubbles. Greater fear predicts lower prices and smaller bubbles. Those traders who remain the most neutral during periods of market volatility achieve the highest earnings. Loss aversion in decision making is correlated with fear, but not with other emotions.
\end{abstract}

Keywords: Bubble, Emotions, Facereading, Face, Crash

JEL Classification: C92, G02

\section{Introduction}

The connection between asset market price movements and emotions has been widely accepted in popular press and commentary. The supposed existence of fear and exuberance as influences on prices is reaffirmed with great frequency in such quarters. Positive emotion is generally associated with booms and high price levels. Alan Greenspan, while chairman of the Federal Reserve, famously remarked that the American stock market exhibited an "irrational exuberance" when it experienced a rapid run up in 1996. The remark betrayed a belief on his part that the increase had, in part, an origin in positive emotions of traders. ${ }^{1}$ Galbraith (1984) describes stock market price bubbles as "speculative euphoria". On the other hand, fear is associated with price variability and cited as a

\footnotetext{
* Breaban: Dept. of Economics and LEE, University Jaume I, Castellon, Spain, email: breaban@uji.es. Noussair: Dept. of Economics, Tilburg University, Tilburg, The Netherlands, email: C.N.Noussair@tilburguniversity.edu. We thank Yen Nguyen for research assistance and comments. We also thank participants at MBEES 2013 and at the 2013 Maastricht Art market symposium for comments. We thank the CentER for Economic Research at Tilburg University and the Generalitat Valenciana (GV/2012/045) and Bancaja Foundation (P11A2010-17) for financial support.

${ }^{1}$ Our notion of happiness is a short-term emotional state, as distinct from a longer-term, more stable state of well-being. Bernanke (2012) clearly articulates this distinction. Happiness is a "Short-term state of awareness that depends on a person's perceptions of one's immediate reality, as well as on immediate external circumstances and outcomes. By "life satisfaction" I mean a longer-term state of contentment and well-being that results from a person's experiences over time."
} 
force leading to selloffs and price declines. Market volatility indices such as the CBOE's VIX, an index of option prices, are referred to colloquially as "fear" indices. The legendary investor Warren Buffett (2008) writes, "A simple rule dictates my buying: be fearful when others are greedy and be greedy when others are fearful", associating the presence of fear in the market with profitable opportunities to make purchases.

There is data supporting the contention that traders' moods can lead to price movements at the market level. Hirshleifer and Shumway (2003) find that good weather is correlated with higher stock returns, while poor weather does not lower returns compared to average weather. They presume that the mechanism whereby this effect operates is through the positive effect that weather has on mood. Kamstra et al. (2003) observe that returns are relatively low in fall and winter and appeal to a similar intuition to explain their results. Sports scores seem to matter for financial returns (Edmans et al., 2007), with home team wins translating to higher prices. Bollen et al. (2010) find that Twitter mood predicts subsequent stock market movements. Gilbert and Karahalios (2009) find that the level of anxiety of posts on the blog site Live Journal also predict movements.

In all cases, more positive emotional states are associated with higher prices. If emotions can increase prices, then they can lead to mispricing well above fundamental values in extreme cases. In this paper we focus on the connection between trader emotions and extreme pricing episodes: asset price bubbles and crashes. We use an experimental approach, which exploits the fact that bubbles and crashes can be reliably created and studied in the laboratory with inexperienced participants. The bubble and crash pattern was first observed in the laboratory with a paradigm introduced by Smith et al. (1988). Subsequent authors have replicated and established the robustness of this price pattern, and the Smith et al. (1988) design has become the dominant experimental paradigm for studying bubbles and crashes. We adhere to this design in the work reported here, and it is described in section three.

Bubbles can be eliminated in this setting when participants are inexperienced, but it requires a very strong framing that deemphasizes the importance of speculative possibilities or a considerable degree of specialized instruction. The magnitude of bubbles is sensitive to environmental parameters such as the amount of liquidity available (Caginalp et al, 1998), institutional factors such as the ability to sell short and the trading institution (Van Boening et al., 1993; Haruvy and Noussair, 2006; Lugovskyy et al., 2012), and the time path of fundamentals (Noussair et al., 2001; Noussair and Powell, 2010; Kirchler et al., 2012; Giusti et al., 2012; Breaban and Noussair, 2013). Nonetheless, there is considerable variation within all conditions that is unexplained. That is, some sessions generate larger bubbles than others despite identical economic structure. We consider here whether variation in the emotional state of participants between different cohorts can account for some of this heterogeneity.

We construct a laboratory environment that is identical to one that is known to induce bubbles and crashes. We use face reading software to track the emotional state of all traders, as captured in 
their facial expressions. The software provides measures of happiness, surprise, anger, disgust, sadness fear, neutrality, and overall emotional valence. According to Elster (1998) emotions can be differentiated from other mental states on the basis of six features: cognitive antecedents, intentional objects, physiological arousal, valence, action tendencies, and physiological expressions. The work we report here focuses on the sixth distinguishing feature of emotion, the physiological, as manifested in facial expressions. We consider several issues. First, at the market level, we study how emotional factors can influence the magnitude of bubbles. We test the hypotheses that a positive emotional state on the part of traders before a market opens predicts higher prices, and that fear predicts lower prices. At the individual level, we consider which emotions are linked to better performance, and ${ }^{2}$ explore the relationship between loss averse decision making and emotional state. Other than one concurrent study on individual decision making (Nguyen and Noussair, 2013), this paper represents the first application of face reading software in experimental finance or economics.

We find a number of strong relationships between emotions, as measured in traders' facial expressions, and market behavior. Positive emotion is associated with higher prices and bigger bubbles. The more positive the valence of the emotions a group of traders exhibits before the market opens, the higher prices are in the subsequent market. Bubbles are driven by exuberance in the sense that at the individual level, making purchases during a boom is positively correlated with current valence. That is, individuals in more positive emotional states make more purchases during a boom. Those who exhibit more neutrality during a crash earn greater profits. We also observe a strong correlation between fear and loss aversion, as registered in a loss aversion measurement task administered before the market opens.

\section{Previous literature}

Moods have been linked to behavior in a number of well-known experimental paradigms, and some of these involve markets. Positive moods can influence product choices (Meloy et al., 2000). Capra et al. (2010) find that positive mood increases bidding in random n-th price auctions in a private value environment. In this type of auction there is a dominant strategy to bid an amount equal to one's valuation and excess bidding is consistent with competitive behavior. Bosman and Riedl (2003) find that negative mood increases bidding in first-price sealed bid auctions, which is consistent with exhibiting more risk averse behavior as a consequence of the negative mood induction. Johnson and Tversky (1983) argue that a positive mood tends to make beliefs more optimistic in the sense that

\footnotetext{
${ }^{2}$ By emotion, we refer to short-term affective states. This is a distinct, though related, phenomenon to that of mood. See Capra (2004) for a discussion. While moods are of relatively low-intensity, diffuse, and enduring affective states without a salient antecedent cause, emotions are more intense and short lived, and they usually have a proximate cause.
} 
probabilities associated with positive events become more distorted in a positive direction. This would push individuals to make less risk averse choices in some settings.

An association between emotion and risk tolerance is one mechanism whereby emotional state could influence market behavior. Asset markets involve the trading of a risky lottery and thus more risk-averse agents would tend to place lower value on the asset, and lead to lower demand and prices. Indeed, Breaban and Noussair (2013) find that more risk-averse cohorts of traders tend to generate lower prices in experimental asset markets. Fellner and Macjekovsky (2007) find that risk aversion on the part of a group of traders is associated with lower trading volume.

Lowenstein et al. (2001) argue that a direct link exists between risk attitude and emotional state, in the sense that emotional reactions to risky situations deviate from the cognitive assessments of those risks, and these emotional reactions can influence decisions in such situations. Lerner and Keltner (2003) find that fear is associated with pessimistic risk assessments and anger with optimistic ones. More pessimistic risk assessments would lead to more risk-averse decisions with respect to objective risks, so that fear would correlate positively with risk aversion. Nguyen and Noussair (2013) find that fear in facial expressions is positively correlated with risk averse choices. Kugler et al. (2012) obtain similar results in a lottery based task that is impersonal. On the other hand, for capital market data, Kliger and Levy (2002) find a negative correlation between mood and risk aversion.

We are aware of three previous studies that explore the role of emotion in generating bubbles in experimental asset markets. All three papers consider markets with the structure of Smith et al. (1988), as we do here. Andrade et al. (2012) induce mood exogenously with film clips before the market opens. Subjects watch video clips that are (a) exciting, pleasant and arousing, (b) neutral, (c) fearful, or (d) sad. They find that the pleasantly exciting video clips are associated with larger bubbles than the other three treatments. The other three conditions are not different from each other in terms of average asset prices.

Lahav and Meer (2010) conduct an experiment with two treatments, which they call the positive and neutral treatments. Like Andrade et al., they induce mood by showing film clips to subjects before the market opens. Positive affect was induced with comedy routines by the performer Jerry Seinfeld, and in the neutral treatment, no clip was shown. They find that the positive treatment is characterized by greater bubbles and higher prices than the neutral treatment, though the neutral treatment still generated price bubbles.

Hargreaves-Heap and Zizzo (2011) conduct an experiment in which a bubble market is created and emotions are tracked over the course of the session. They focus on the emotions of anger, anxiety, excitement and joy. They have four conditions. In all conditions, participants complete two asset markets. In two of the treatments, individuals rate, on a Likert scale from $1-7$, how intensely they current feel each of the four emotions. In one of these conditions, subjects can chat with each other, and in the other they cannot chat. Hargreaves-Heap and Zizzo report that eliciting emotions does not in itself have an effect on market prices, but they find that the level of excitement reported is 
positively correlated with price level. They also find that buying assets is linked to excitement and selling assets is connected to anxiety. They do not find a correlation between emotional state and trading profits. The work of Andrade et al. (2012), Lahav and Meer (2010), and Hargreaves-Heap and Zizzo (2012) serves as the source of our first hypothesis, described in section four, that positive emotional valence on the part of traders is associated with higher prices.

Another of our hypotheses is based on a finding of Lo et al. (2005) and Lo and Repin (2002). These studies consider how emotions affect trading behavior and performance in a field setting. They follow a sample of individuals enrolled in a day trading course, and administer a survey to these traders after each day of trading. The survey asks several questions about emotional state. The authors report that those who exhibit emotions that respond more to short-term price movements in time periods of market turbulence earn less money and trade more than those who exhibit a weak emotional response. This observation serves as the origin of our fourth hypothesis, which is that those individuals who have a more neutral emotional state during a crash have greater earnings.

\section{The experiment}

\subsection{Experimental design and available data}

The structure of the market was based on the paradigm created and studied in Smith et al. (1988). The asset that was exchanged in the market had a finite lifespan of $T$ periods. At the end of each period $t \in\{1, \ldots, T\}$, each unit of the asset paid a dividend $d_{t}$ that was independently drawn from a distribution that was identical for all periods. In any period $t$ the expected dividend $E\left(d_{t}\right)$ on a unit of the asset was equal to the expected value of the dividend distribution. Dividends were drawn independently in each period. Therefore, the expected future dividend stream at time $t, E\left[\sum_{t}^{T} d_{t}\right]$, equaled the expected period dividend multiplied by the number of periods remaining in the life of the asset. In other words, $E\left[\sum_{t}^{T} d_{t}\right]=(T-t+1) E\left(d_{t}\right)$.

Since dividends were the only source of intrinsic value for the asset, the fundamental value $f_{t}$ had a particularly simple structure. It was equal, at any time $t$, to the expected future dividend stream from time $t$ onward. In other words, $f_{t}=(T-t+1) E\left(d_{t}\right)$. In our markets, the life of the asset was $T=$ 15 , and the dividend was $d_{t} \in\{0,8,28,60\}$, where each realization was equally likely, for all $t$. Thus, $E\left(d_{t}\right)=24$, and $f_{t}=24(16-t)=384-24 * t$ at time $t$. The dividend distribution had a standard deviation of 27 per period, which was greater than the expected dividend. Therefore, risk-averse traders could value the asset at considerably less than its fundamental value. 
In each period, each trader had the ability to trade units of the asset for cash with any other trader in an open market, provided that he always maintained non-negative cash and share balances. Transaction prices were determined in a continuous double-auction market (Smith, 1962). This type of market operates in the following manner. Each period, the market is open for a fixed time interval, which was two minutes in this experiment. At any time while the market is open, any trader can submit an offer to sell or to purchase a share. These offers are posted publicly on all traders' computer screens. Also at any time, any trader can accept an offer that another trader has submitted. When a bid or ask is accepted by a trader, a transaction for one share takes place between the trader who posted the offer and the trader who accepted it. Thus, within a period, it was possible for different transactions to occur at different prices. An individual could trade as much as he wished provided he has sufficient cash and units of the asset to complete the trades.

Each subject had an identical portfolio, consisting of an initial endowment of 5 units of asset, and 5000 units of experimental currency, at the beginning of period 1. A subject's final earnings in the market were equal to the cash he had at the end of the experiment, which corresponded to his initial cash, plus the value of dividends received, plus (minus) any profit (loss) from trading. The market was computerized and used the Ztree program developed at the University of Zurich (Fischbacher, 2007).

Prior to the opening of the asset market, we administered the loss aversion measurement task used by Trautmann and Vlahu (2007), which is based on an earlier protocol of Fehr and Goette (2007). This task consisted of a series of six choices, presented in a price list format. Each choice offered the opportunity to play a gamble which paid 4.5 Euro with probability .5 and either $-0.5,-1.5$, $-2.5,-3.5,-4.5$ or -5.5 Euro with probability .5 , with each choice appearing exactly once. Subjects were required to indicate whether or not they accepted to play each of the six gambles. The number of gambles one decided not to play is interpreted as a measure of her loss aversion.

Subjects completed the task using pen and paper. They submitted all six of their decisions simultaneously when they turned in their completed sheet of paper to the experimenter. They were informed prior to beginning the task that only one of the decisions would count toward their earnings. After all decisions were turned in, a die was rolled. The outcome of the roll determined which decision would count for each participant. If a subject had chosen not to play the relevant gamble, she received a payoff of zero for this part of the experiment. If a participant chose to accept the selected gamble, a coin was flipped to determine whether she received 4.5 Euro or the negative payment specified in the gamble. ${ }^{3}$ A separate coin was flipped for each participant who chose the gamble.

Our dataset consists of eight sessions. The sessions were conducted at Tilburg University and all subjects were students at the university. Subjects were recruited via an online system. No subject participated in more than one session of the experiment. On average, the sessions lasted one hour.

\footnotetext{
${ }^{3}$ Some subjects experienced real losses in this part of the experiment. However, they were informed that there would be subsequent activities in the session in which they could expect to earn money on average. No subject ended the session with negative final earnings, because income in the market phase of the experiment in all cases more than fully offset losses incurred in the loss aversion measurement task
} 
Between six and 11 traders participated in each session, with an average of eight subjects per session. Participants' earnings from the asset market were converted to Euro at a rate of 500 units of experimental currency to 1 Euro. This resulted in an average payment of 15.6 euros (including the loss aversion measurement task).

\subsection{The Facereader software}

During the sessions, all subjects were videotaped and the videotapes were analyzed later with Noldus Facereader. The taping began at least 30 seconds before the opening of the market for the first period and continued continuously until the session ended.

Facereader operates in the following manner. The position of the face in an image is found using a method called the Active Template Method (ATM). This method places a template over an image and calculates the most likely position of the face. A second algorithm for face finding, the Viola Jones cascaded classifier algorithm, takes over when the Active Template Method cannot locate a face. A model called the Active Appearance Model (AAM) describes the location of 55 key points in the face and the facial texture of the convex hull defined by these points. The model uses a database of several thousand annotated images and calculates the main sources of variation found in the images. Principal Component Analysis is used to reduce the model's dimensionality. The classification of the facial expressions is done with an artificial neural network, which takes the vector of 55 locations on the face as input. The network was trained with roughly 2000 images of different individuals to classify the extent to which a face expresses the six basic universal emotions of happiness, surprise, anger, disgust, sadness and fear, as well as neutrality.

The output of Facereader is in terms of graphics and text. This software's quantitative output is a vector of values for the seven emotions and an overall valence of emotional state. The possible values of each emotion range from 0 to 1 , and valence ranges from -1 to +1 . The values are registered five times per second. Figure 1 illustrates graphically an example of the output of Face Reader. As the video is analyzed, the two charts on the right of the figure indicate, in real time in both bar graph and time series format, the extent to which each of the six basic emotions (as well as neutrality) is reflected in the facial expression. A pie chart, in the lower portion of the figure, shows the average intensity of each emotion. These values are normalized so that the sum over all emotions equals 1 . The valence is an overall measure of whether the individual's emotional state is currently positive or negative. It is given as a time series in the upper middle portion of the screen. The measure compares the conformity of the facial expression to 'Happy', the only positive emotion, with that to the four negative emotions. Facereader output tends to identify the intended emotion of an individual with a high degree of success (Uyl and Kuilenberg, 2005). It also corresponds closely to observers' evaluations of the faces considered (Terzis et al., 2010). 
This is the first study to employ face reading in experimental finance. In our opinion, face reading is especially well-suited to the study of emotions for several reasons. The first reason is that it classifies an individual's physiological state along emotional dimensions in a quantitative manner. This allows us, for example, to claim that one stimulus provokes more disgust but less sadness than another, or that a particular decision is taken when an individual is surprised rather than angry. A second advantage is that it registers emotional measurement in a manner that is completely unobtrusive to the participant, and data acquisition would proceed unnoticed if the individual were not informed that it was occurring. ${ }^{4}$

The third reason is that the facial expressions corresponding to the six basic emotions appear to be universal (Ekman and Friesen, 1984). These expressions accompanying these emotions are common to all cultures and primates (Ekman, 1997). They are the same for blind and sighted individuals (Matsumoto and Willingham, 2009), which provides strong evidence that they are innate. This means that results of studies such as ours should be replicable in different population groups and cultures. Happiness is positive in valence, surprise is neutral, and the other four are negative. Happiness and anger are approach emotions, which tend to lead an individual to move toward the situation that triggers the emotion. Sadness, disgust, and fear, are withdrawal emotions, meaning that an individual typically seeks to avoid the stimulus that induces these emotions.

\section{Hypotheses}

We advance several hypotheses about the relationships between emotions and market behavior. Most of the hypotheses emerge from previous work. This first is suggested by the previous studies of Lahav and Meer (2010), Andrade et al. (2012) and Hargreaves-Heap and Zizzo (2012). We hypothesize that the more positive the emotions that traders exhibit before a market opens, the greater the price level in the market. Thus, we hypothesize that positive emotion is positively related to subsequent price, and thus in all likelihood within our setting, to greater bubbles. This pattern is also suggested by previous work on auctions, which concludes that positive mood is associated with higher bidding (Capra et al., 2010).

Hypothesis 1: More positive initial emotional valence predicts greater subsequent prices and a larger bubble.

\footnotetext{
${ }^{4}$ Subjects were aware that they were being videotaped but not that there videotapes were to be analyzed with facereading software.
} 
To test this hypothesis, we check whether there is a correlation between (a) the average emotional valence within a group of traders in the 30 seconds before their market opens for period one, and (b) the average price over the 15 periods the market is open. Valence is a net measure of positivity of emotional state.

We also consider whether fear predicts lower prices. That it should do so is intuitive. However, Andrade et al. (2012) fail to detect an effect, since their attempt to induce fear generates similar results to a market in which emotions were not induced. However, Hargreaves-Heap and Zizzo do find that anxiety, a closely related emotional state, is correlated with lower prices. To the extent that fear is associated with risk aversion (see Lerner and Keltner, 2001, or Nguyen and Noussair, 2013), fear would lead to lower pricing of the lottery that corresponds to the price of the asset. Furthermore, it is possible that those who experience fear would be less likely to take on the risk associated with speculation, speculative demand would be reduced, and fear would have the effect of lowering prices.

Hypothesis 2: Greater Fear on the part of the average trader before the market opens is correlated with lower subsequent prices.

Hypothesis 1 and 2 were concerned with the average valence and fear present before any activity has taken place. The next hypothesis considers the relationship between emotions and activity during a bubble. We consider the period during which prices exhibit the greatest average increase, and denote this as the boom period. If there is "exuberance" driving demand and pushing up prices during a bubble, the common view expressed by commentators, one would expect to observe those individuals who have more positive emotional valence during the boom period making the most purchases. Hypothesis three is that this pattern would appear in our data.

Hypothesis 3: Booms: During a boom, individuals with more positive valence make greater net purchases.

While hypothesis 3 relates to booms, hypothesis 4 has to do with the emotional correlates of crashes. Hypothesis 4 consists of three parts. The first has to do with the overall strength of emotions during a crash and trader profits. Lo and Repin (2002) and Lo et al. (2005) find that those who exhibit less volatility in their emotional state in the face of fluctuations in the market have greater earnings. In our experiment, the analogy would be a hypothesis that the level of neutrality in one's facial expression is correlated with greater trading profits. The second and third parts of the hypothesis concern the emotions associated with the rapid decrease in asset value that occurs during a crash. Those who have more units of asset incur greater losses during a crash than those with fewer units. We hypothesize that two distinct emotional episodes accompany a crash. During the market freeze-up 
and price decline, there is fear. This fear is presumably greater for those individuals who hold more units of the asset, as they have more at risk and are therefore losing more during the crash. At the end of a crash, there is less uncertainty and the consequences of the crash are known. Those who hold more units have incurred the greatest losses. Thus we expect the negative emotions that appear after adverse events: anger, disgust and sadness (fear appears in anticipation of a possible adverse event) to be positively correlated with how many units an individual holds at the end of a crash.

Hypothesis 4: Crashes: (a) Traders who exhibit greater neutrality during a crash achieve greater earnings. (b) Traders who hold more units during a crash exhibit more fear. (c) Traders who hold more units after a crash experience more anger, disgust, and sadness.

\section{Results}

The time series of transaction prices in each of the eight sessions is shown in figure $2 \mathrm{a}$, along with the time path of fundamental value. In the figure, the vertical axis is in terms of experimental currency, and the horizontal axis indicates the market period. As can be seen in the figure, there are large differences between sessions, but in most sessions the bubble and crash pattern is observed. Typically, prices remain above fundamental values for a considerable period of time, and then exhibit a rapid fall toward fundamental value.

[Figures 2a and 2b: About Here]

Figure $2 \mathrm{~b}$ illustrates the standard deviation of prices within each period, by session. Because the double auction market system allows trades to be concluded at different prices within a market period, the standard deviation of prices within a period can be substantial. This is especially the case during an episode of rapid price movement, such as a crash. The figure shows a consistent pattern. While the standard deviation differs by session, it tends to be greatest at the beginning of the life of the asset and during the crash. It is smallest near the end of the asset's life, when prices adhere relatively closely to fundamental values.

The relationship between a bubble and crash episode and the dynamics of emotion is illustrated in figures $3 \mathrm{a}-3 \mathrm{c}$. The data are from session 8 , which exhibits a particularly large and obvious bubble and crash. The first two panels show that a crash occurs in period 11, and the crash is accompanied by a surge in price variance. In the third panel, the strength of the average level of several emotions that members of the session cohort exhibit over period $10-12$, the periods just before and during the crash, is plotted. These emotions are anger, fear, happiness, and surprise. They are normalized at the levels observed in period 10 , just before the onset of the crash. 
The data show a clear pattern. Sadness and anger exhibit modest increases during a crash as traders' paper wealth declines. However, fear and surprise exhibit sharp increases, as uncertainty increases. By period 12, when the crash is ending, surprise has fallen sharply, and fear has decreased modestly. However, sadness and anger continue to increase, as traders realize the extent of the losses the crash has created. The figure illustrates the existence of an emotional reaction to a key market event and the ability of Facereader to coherently characterize this reaction. ${ }^{5}$

We now evaluate the hypotheses advanced in section three. The first two hypotheses are about the relationship between the initial emotional profile and the overall price pattern, and are summarized as results 1 and 2 .

\section{Result 1: A more positive emotional state before the market opens is positively correlated with subsequent market price level.}

Support for Result 1: We take the average valence that Facereader measures over the 30 -second interval before the market opens for each subject. We then average it for all subjects in a session. Then we correlate the average for a session with the average amount that price exceeds fundamental value over the course of the session ${ }^{6}$. Figure 4 below plots the average initial group valence against the average price level over the 15-period life of the asset. The figure shows a clear positive relationship between emotional state and price. The Spearman correlation between valence in a session and average price level in the session is $\rho=0.6190(p=.01) .^{7}$

[Figures 4 and 5: About Here]

\section{Result 2: Average trader fear before the market opens is negatively correlated with price level in the market.}

\footnotetext{
${ }^{5}$ The facial expression data exhibit several broad characteristics. The first is that the valence is typically negative. This likely means that participation in experiments yields disutility for participants compared to other activities. There is great volatility in emotional state even over short time intervals. This may reflect the large number and heterogeneity of events that one experiences in a period. There is no discernible decline in the overall strength of emotion over time, over the roughly 35-minute horizon that constitutes the experiment. Anger tends to be greater at the outset, possibly reflecting the fact that individuals who are concentrating tend to look like they are angry (see Zaman and Shrimpton-Smith, 2006), but within a few minutes it stabilizes. Valence reflects this pattern, typically being very negative at the very beginning of a session but stabilizing at a moderately negative level for the rest of the session.

${ }^{6}$ The same results would obtain if we used the average price difference from fundamentals $p_{t}-f_{t}$. This difference is referred to as the Bias in a market by Haruvy and Noussair (2006).

${ }^{7}$ The correlation between the variance of valence among participants before a session begins, and the volume of trade over the entire session, is .12, and is not significant at conventional levels.
} 
Support for result 2: The relationship between the average fear a cohort expresses before the market opens and price level over the subsequent market is very pronounced. Figure 5 relates the fear that Facereader registers in the average trader in a given session to the average price in the session. The figure shows a strong negative relationship between the two variables. The correlation is highly significant $(\rho=-0.8333, p=0.01)$.

Indeed, each of the seven emotions considered separately correlates with subsequent price level. The four negative emotions, sadness, anger, fear, and disgust, correlate negatively with price level with $\rho=-.381,-.428,-833$, and -.333 , respectively, while happiness and neutrality correlate positively with price level at $\rho=.476$ and .357 . While none of these correlations are significant, they are consistent with higher (lower) prices being associated with positive (negative) emotional states.

We now consider hypothesis three, which relates individuals' emotional valence to their behavior during a boom. The boom period of a session is defined as the period with the greatest net price increase over the immediately preceding period, that is, the period $t$ that maximizes $p_{t}-p_{t-1}$ within a session. Figure 6 shows the level of valence on the horizontal axis for each individual in the eight sessions, and the net change in her holding of shares within a period. The data are from the twominute boom period of each session. The figure suggests the pattern described in result 3 .

[Figure 6: About Here]

\section{Result 3: During a boom, valence is positively correlated with net purchases}

Support for result 3: The correlation between $v_{i t}$, the valence of individual $i$ in period $t$, and $s_{i t}-s_{i t-1}$, the next purchases of individual $i$ in period $t\left(s_{i t}\right.$ is the quantity of asset individual $i$ holds at the end of period $t)$ during the boom period is $0.323(p=0.026)$.

A number of interesting related patterns also appear in the data. The correlation between happiness and net purchases in the boom period $t$ is also significant $(\rho=0.3010, p=0.04)$. However, the correlation between net purchases in the boom period and fear is close to zero $(\rho=0.0188, p=$ $0.9)$. Average valence is not greater on average during a boom than at other times. Before the market opens it averages -.18 , during the boom period it equals an average of -.29 , and during crash it is -.28

The first part of the hypothesis four is that more neutrality during a crash is correlated with greater average earnings. Figure 7 plots the relationship between the level of neutrality individuals exhibit during a crash period, which we define as the period with the greatest price decrease from the preceding period, and the final earnings an individual accrues over the entire 15-period market. The 
figure suggests that more neutrality during a crash is correlated with better performance. The support for result 4 confirms this impression. In addition, the hypothesis postulates that at the individual level, the number of units held during the crash period, which measures the amount of paper losses incurred during the period, correlates with the four negative emotions. However, we observe that none of these negative emotions is related to the extent of these losses.

[Figure 7: About Here]

Result 4: Traders who exhibit greater neutrality during a crash achieve higher earnings.

Support for result 4: The correlation, at the level of the individual, between her average neutrality during the crash period and her final earnings is $0.205(p=0.16)$. Neutrality correlates negatively with units held at the end of the crash period at $\rho=-.27(p=.064)$. The other emotions do not correlate with the number of units held, and thus the amount of unrealized capital losses, during a crash. The results are similar if the units held at the beginning of the crash period are considered (very few units are exchanged during a crash because of very low demand).

The last result, five, describes a strong correlation between loss aversion and fear. The loss aversion protocol that was administered at the beginning of the sessions, and the measurement of the emotional profile of individuals before the market opens, permit an analysis of the correlation between loss aversion and the emotional state of participants at the individual level that is independent of any experience on the market. As summarized in result 5, those who make more loss-averse decisions exhibit more fear in their facial expressions, and have a more negative overall emotional state. There is no correlation between loss aversion and any other of the six basic emotions or with neutrality.

Result 5: Individuals who exhibit more fear make more loss-averse decisions. Loss aversion is not significantly correlated with anger, happiness, sadness, disgust, surprise or neutrality. Loss aversion is negatively correlated with the valence of emotional state.

Support for Result 5: Table 1 contains the correlations between the number of gambles declined in the loss aversion task and the average consistency of facial expressions with each of the six emotions that Facereader registers in the 30 seconds before the market opens. A greater number of gambles declined indicates greater loss aversion. The table shows that the correlation between fear and loss 
aversion, .3427 , is positive and significant at the $\mathrm{p}<.05$ level. The correlation between loss aversion and valence is negative $(\rho=-.3012, p<.05)$. In contrast, none of the correlations with other emotions are significant at even the $10 \%$ level.

We now study the feedback between an individual's performance in the market and her emotional state. Define the value of an individual's asset/cash position at any point in time as $w_{i t}=c_{i t}$ $+p_{t} s_{i t}$, where $w_{i t}$ is an individual's wealth at time $t, c_{i t}$ is the cash that $i$ has at the end of period $t$, and $s_{i t}$ is the quantity of units he holds. We conjecture that valence, as well as happiness, would be positively correlated with current wealth, which can be measured as the level of cash the player has at present, plus the market value of one's shares. Of course, it is possible that emotional feedback occurs exclusively through the price level or through cash holdings, and in that case the correlation would be only present for $c_{i t}$ or $p_{t}$. We also conjecture that a subset of the negative emotions of fear, anger, disgust, and sadness, evaluated at time $t$, would be negatively correlated with wealth at time $t$. The regression reported in table 2 considers these effects, and is the basis for result 6 .

[Tables 1 and 2: About Here]

Result 6: Greater wealth is correlated with more positive emotional valence. Decomposing this effect into component emotions reveals that price level is positively correlated with happiness, while negatively correlated with anger. Cash holdings are negatively correlated with fear.

Support for Result 6: Table 2 shows all of the significant effects of current wealth, price level, price volatility and gender on each emotion. Overall valence is influenced by wealth and price, with greater wealth and higher prices associated with more positive valence. Controlling for market variables, women have more positive valence than men. Greater wealth is associated with more happiness and less fear. More cash is also correlated with lower fear. Women are less fearful than men. While price volatility is positively correlated with fear, it is not significant in this regression.

\section{Conclusion}

In this paper, we study the connection between emotions and asset market prices. We find a number of patterns that conform to commonly expressed intuition about the link between emotion and asset prices. When traders are in a more positive emotional state at the time the market opens, asset prices are higher. When they feel more fear, prices are lower. Traders in a relatively positive 
emotional state are the ones making purchases during a boom. Those who keep a neutral emotional state during a crash earn greater profits.

A number of factors have been shown to influence the incidence and magnitude of bubbles in the laboratory. These include the institutional structure, the time path of fundamentals, and the risk aversion, loss aversion, and cognitive ability of traders. The results reported here show that another factor can be added to the list; the emotional state of traders. This finding is in agreement with similar results that have recently appeared in the literature (Lahav and Meer, 2010; Andrade et al., 2012; Hargreaves-Heap and Zizzo, 2012). Thus, it is becoming clear that asset price bubbles in experimental markets are a complex phenomenon, subject to many determining influences.

We find a strong correlation between fear and loss aversion. Such a connection is, in our view, quite natural and intuitive. Those who anticipate that they will have a more negative response to a financial loss exhibit more fear when placed in a situation in which losses are possible, and thus make decisions in such a manner as to minimize the likelihood of their occurrence.

This study is the first application of face reading to experimental finance. This methodology had yielded what are, in our view, coherent results. Our view is that the strength of our results contributes to the validation of the methodology. We believe that Facereading has considerable potential for the study of markets. In starker experimental settings than the one studied here, the emotional response to specific events, such as to a price quote one has received, or to a specific transaction one has made or observed, can be isolated and studied. In particular, in future work, face reading can be used to study face-to-face market transactions. In such situations, facial cues are important sources of information about the intentions and emotional state of other parties to a potential transaction. In these settings, individuals may try to manipulate their facial expression as part of their strategy to obtain more favorable terms. Face reading technology is highly conducive to the study of such behavior.

\section{References}

Andrade E., S. Lin, and T. Odean (2012), "Bubbling with Excitement: An Experiment”, working paper, University of California at Berkeley.

Bernanke, B. (2012), Excerpt from speech at the $32^{\text {nd }}$ General Conference of the International Association of Income and Wealth, Cambridge, MA, USA, August 6, 2012.

Bollen, J., H, Mao and X. Zeng (2011), “Twitter Mood Predicts the Stock Market”, Journal of Computational Science 2, $1-8$.

Bosman R. and A. Riedl (2003), "Emotions and Shocks in a First-Price Sealed Bid Auction", working paper, Maastricht University.

Breaban A. and C. N. Noussair (2013), "Fundamental Value Time Paths and Pricing in Experimental Asset Markets", mimeo, Tilburg University. 
Buffett, W. (2008), “Buy American. I Am”, The New York Times, October 16.

Caginalp, G., Porter, D. and Smith, V. (1998) "Initial Cash/Asset Ratio and Asset Prices: An

Experimental Study", Proeedings of the National Academy of Science 95, 756-761.

Capra M. (2004) "Mood Driven Behavior in Strategic Interactions" American Economic Review, 94(2), 387-372

Capra M., K. Lanier, and S. Meer (2010) "The Effects of Induced Mood on Behavior in Random Nth Price Auctions", Journal of Economic Behavior and Organization 7(2), 223-234.

Eckel C. and R. Petrie (2011) “Face Value,” American Economic Review, 101(4), 1497-1513.

Edmans E., D. Garcia and O. Norli (2007), "Sports Sentiment and Stock Returns", Journal of Finance 62(4), 1967-1998

Ekman, P. (2007), "Emotions Revealed, Recognizing Faces and Feelings to Improve Communication and Emotional Life". Henry Holt and Company, New York.

Ekman P. and W. V. Friesen (1986), "A New Pan-cultural Expression of Emotion", Motivation and Emotion, 10, 159-168

Elster J. (1998), “Emotions and Economic Theory”, Journal of Economic Literature 36, 47-74

Fellner G. and B Maciejekovsky (2007), "Risk Attitude and Market Behavior: Evidence from Experimental Asset Markets," Journal of Economic Psychology, 28(3), 338-350

Fischbacher U. (2007), z-Tree: Zurich Toolbox for Ready-made Economic Experiments, Experimental Economics 10(2), 171-178.

Galbraith J. K. (1984), “A Short History of Financial Euphoria”, Penguin Books, UK.

Gilbert, E. and Karahalios, K. (2010). "Widespread Worry and the Stock Market", 4th International AAAI Conference on Weblogs and Social Media.

Giusti, G., J. Jiang, and Y. Xu (2012), "Eliminating Laboratory Asset Bubbles by Paying Interest on Cash”, Working Paper, Bank of Canada.

Hargreaves-Heap and D. Zizzo (2012), "Emotions and Chat in a Financial Markets Experiment", working paper, University of East Anglia.

Haruvy, E., Lahav, Y. and Noussair, C. N. (2007) "Traders' Expectations in Asset Markets: Experimental Evidence”, American Economic Review, 97(5), 1901-1920.

Haruvy, E. and C. Noussair (2006), "The Effect of Short Selling on Bubbles and Crashes in Experimental Spot Asset Markets", Journal of Finance 61, 1119-1157.

Hirshleifer D. and T. Shumway (2003), "Good Day Sunshine: Stock Returns and the Weather", Journal of Finance, 3 (6), 1009 - 1032.

Johnson E.J., Tversky A. (1983), "Affect, Generalization, and the Perception of Risk", Journal of Personality and Social Psychology, vol. 45: p. 20-31

Kamstra, M.J., L.A. Kramer, and M.D. Levi (2003) "Winter Blues: A SAD Stock Market Cycle", American Economic Review 93, 324-343. 
Kirchler, M., Huber, J., Stöckl, T. (2012), "Thar She Bursts - Reducing Confusion Reduces Bubbles", American Economic Review 102(2): 865-883

Kliger D. and O. Levy (2003) "Mood-Induced Variation in Risk Preferences", Journal of Economic Behavior and Organization 52(4), 573 - 584.

Kugler T., Connolly T., Ordonez L.D. (2012) "Emotion, Decision, and Risk: Betting on Gambles versus Betting on People", Journal of Behavioral Decision Making 25: 123 - 145.

Lahav, Y. and S. Meer (2010), "The Effect of Induced Mood on Prices in Asset Prices: Experimental Evidence", working paper, Ben Gurion University of the Negev.

Lerner J.S., Keltner D., (2001). "Fear, Anger and Risk", Journal of Personality and Social Psychology 81(1). 146-159

Lerner J.S., Small D.A., Loewenstein G., 2004. "Heart Strings and Purse Strings: Carryover Effects of Emotions on Economic Decisions", Psychological Science, 15, 337-341

Lo A., D. Repin and B. Steenbarger (2005), Fear and Greed in Financial Markets: A Clinical Study of Day Traders", American Economic Review 95(2), 352 - 359.

Lo A. and D. Repin (2002) “The Psychophysiology of Real-Time Financial Risk Processing." Journal of Cognitive Neuroscience, 14(3), pp. 323-39.

Loewenstein, G., E. Weber, C. Hsee, and N. Welch (2001), "Risk as feelings" Psychological Bulletin. $127,267-286$.

Lugovskyy, V., Puzzello, D., and Tucker, S. (2011). “An Experimental Study of Bubble Formation in Asset Markets Using the Tatonnement Trading Institution”, Working Paper 07/2011, Canterbury University.

Matsumoto, D., and Willingham, B. (2009), "Spontaneous Facial Expressions of Emotion of Blind Individuals", Journal of Personality and Social Psychology, 96(1), 1-10.

Meloy M. (2000), "Mood-Driven Distortion of Product Information", Journal of Consumer Research, $27(3), 345-359$.

Nguyen, Y. and Noussair C. N. (2013), "Risk aversion and Fear". working paper, Tilburg University

Noussair C. N., S. Robin and B. Ruffieux (2001) "Price Bubbles in Laboratory Asset Markets with Constant Fundamental Values", Experimental Economics 4(1), 87-105.

Noussair C. N. and O. Powell (2010) "Peaks and Valleys: Price Discovery in Experimental Asset Markets with Non-Monotonic Fundamentals", Journal of Economic Studies, 152-180

Smith, V. (1962). An Experimental Study of Competitive Market Behavior. Journal of Political Economy 70(2): 111-37.

Smith, V., G. Suchanek, and A. Williams (1988) Bubbles, Crashes, and Endogenous Expectations in Experimental Spot Asset Markets, Econometrica, 56, 1119-1151.

Terzis, V., C. Moridis, and A. Economides (2010). Measuring Instant Emotions During a SelfAssessment Test: The Use of FaceReader. Proceedings of Measuring Behavior, 192-195. 
Trautmann, S., and Vlahu, R (2011). Strategic Loan Defaults and Coordination: An Experimental Analysis. Working paper, Dutch National Bank.

Den Uyl M.J. and H. van Kuilenburg (2005) "The FaceReader: Online Facial Expression Recognition", Proceedings of Measuring Behavior, 589-590

Van Boening, M., A. Williams, and S. LaMaster (1993), "Price Bubbles and Crashes in Experimental Call Markets", Economics Letters 41, 179-185.

Zaman B. and T. Shrimpton-Smith (2006), "The FaceReader: Measuring Instant Fun of Use", NordiCHI, 457-460 
Table 1: Correlations Between Loss Aversion Measure and Emotions

\begin{tabular}{ccccccccc} 
& Fear & Valence & Happiness & Anger & Surprise & Disgust & Sadness & Neutral \\
\hline Loss & $0.3427 * * *$ & $-0.3012 * *$ & -0.0459 & -0.0680 & -0.0851 & 0.2098 & 0.1096 & -0.1989 \\
aversion & $(0.018)$ & $(0.025)$ & $(0.759)$ & $(0.649)$ & $(0.569)$ & $(0.157)$ & $(0.463)$ & $(0.180)$ \\
\hline
\end{tabular}

$* * *$ correlation significant at $\mathrm{p}<.01$

$* *$ correlation significant at $\mathrm{p}<.05$

Number of observations: 55 
Table 2: Emotional Correlates of Wealth, Cash Balance, Price Level, Volatility, and Gender

\begin{tabular}{lllllll} 
& Valence & Happiness & Anger & Fear & Surprise & Disgust \\
\hline Wealth & $.000087^{* * *}$ & $.0000433^{* *}$ & & $-.0000602^{*}$ & & \\
Cash & & & $-.0000112^{* *}$ & $.0001525^{* * *}$ & \\
Price level & $.0001226^{* * *}$ & $.0000739^{* * *}$ & $-.0000664^{* *}$ & & $-.0007913^{* *}$ & \\
Price volatility & & & & & & \\
Gender & $.0645256^{* *}$ & & & $-.0511802^{* *}$ & $.8103853^{* * *}$ & $.0748292^{* * *}$ \\
\hline
\end{tabular}

$* * *$ correlation significant at $\mathrm{p}<.01$

$* *$ correlation significant at $\mathrm{p}<.05$

* correlation significant at $\mathrm{p}<.10$ 


\section{Figure 1: Facereader Output}

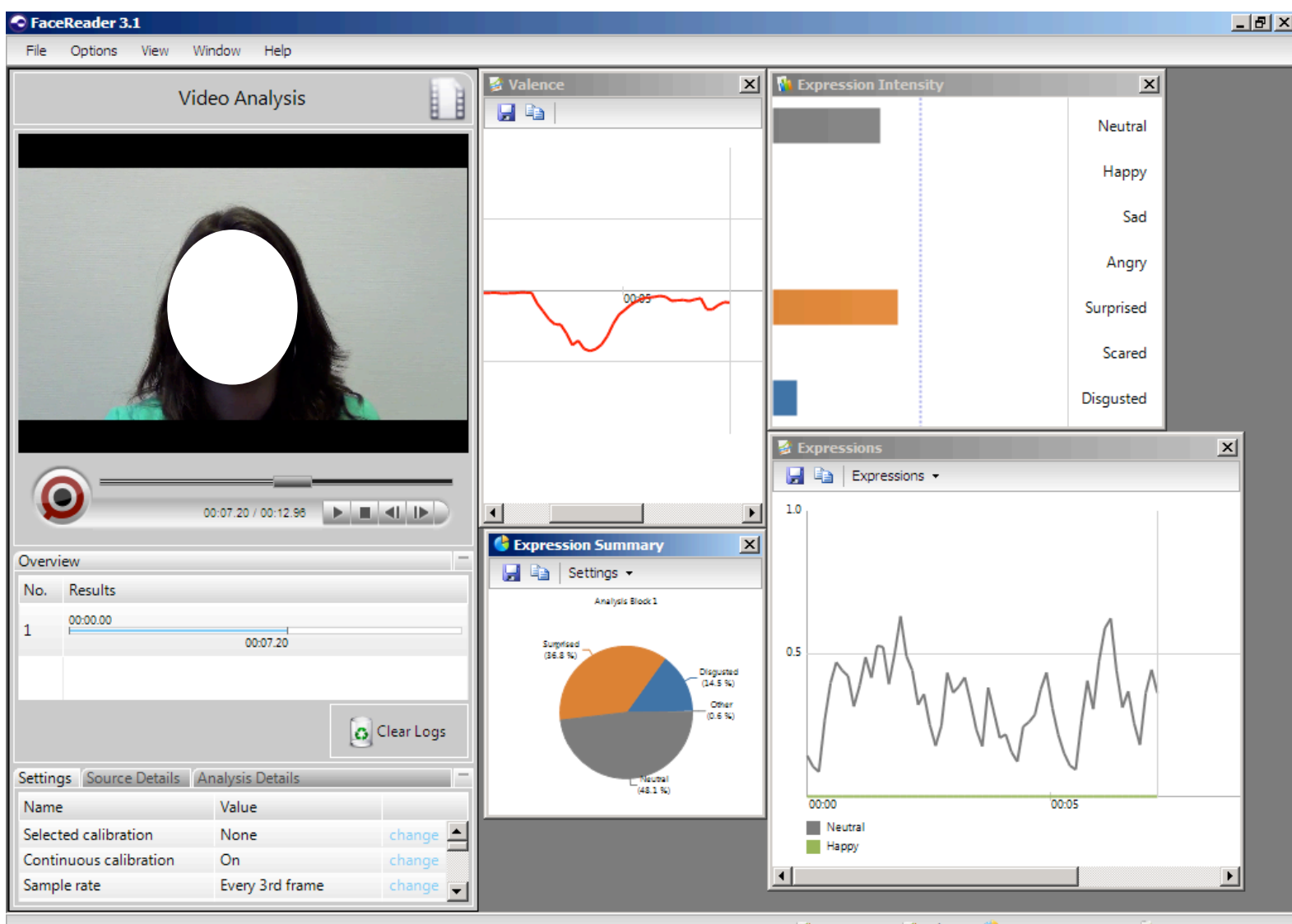

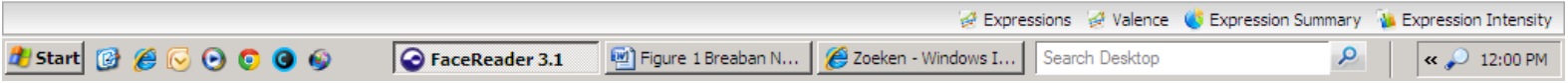


Figure 2a: Average Transaction Price, All Periods, All Markets

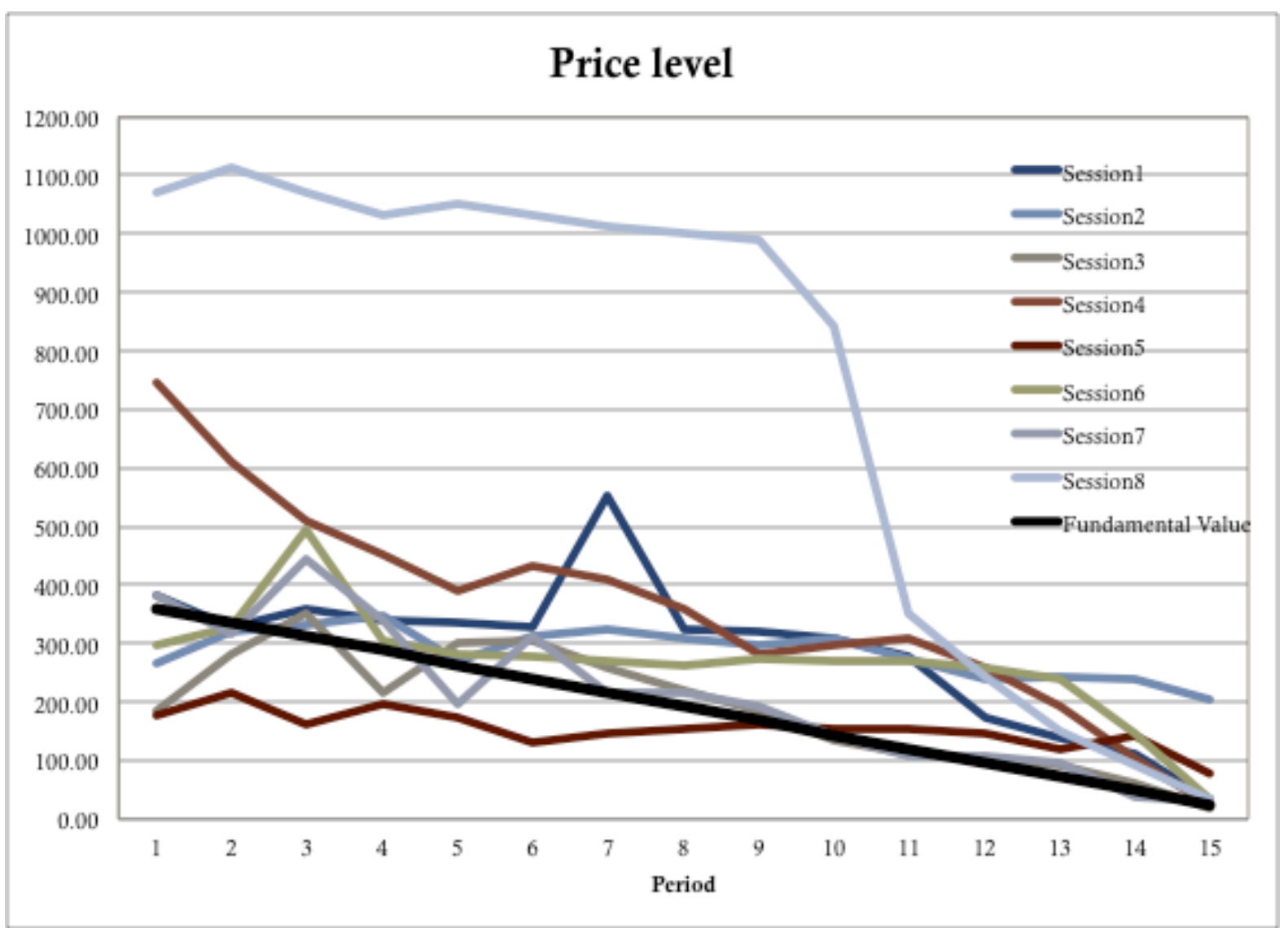

Average over all trades in period, one time series for each session. 
Figure 2b: Standard Deviation of Transaction Price, All Periods, All Markets

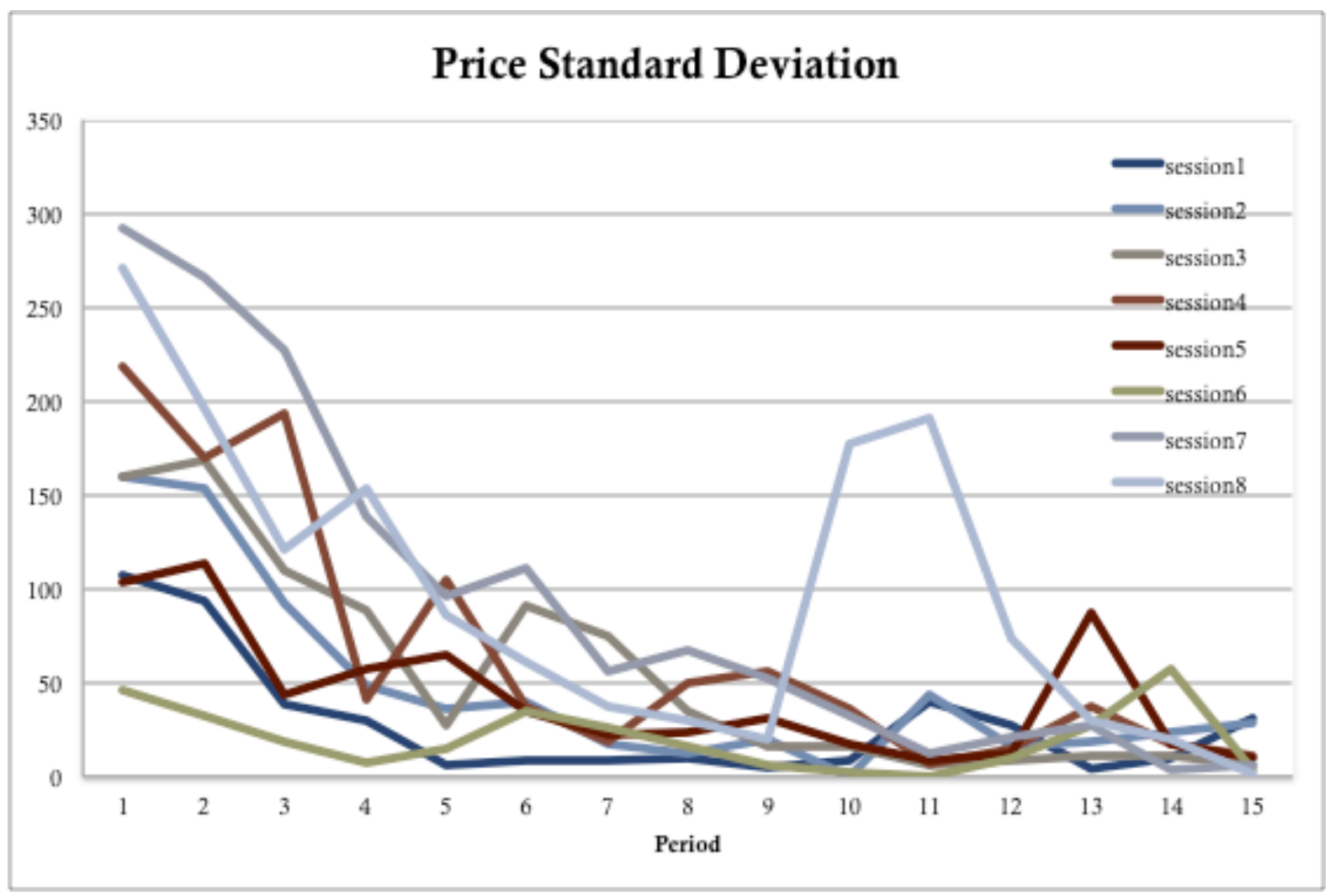

Standard deviation within periods, one time series for each session. 
Figures $3 \mathrm{a}-3 \mathrm{c}$ : Market 8 , time series of mean transaction price, standard deviation of price, and emotions
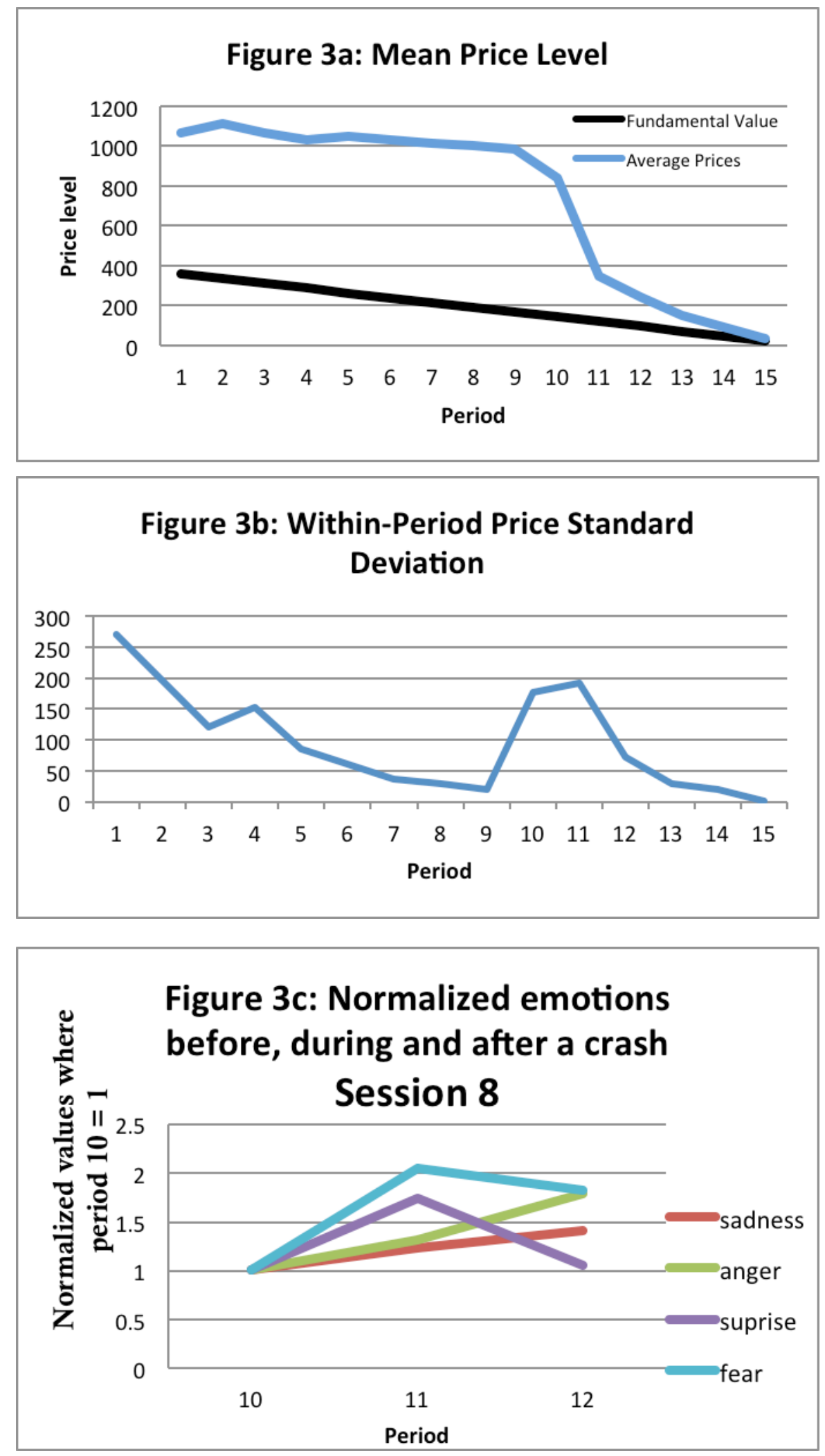

Averaged emotions over entire period, registered at intervals of 0.2 seconds. 
Figure 4: Emotional Valence Prior to Market Open and Price Level

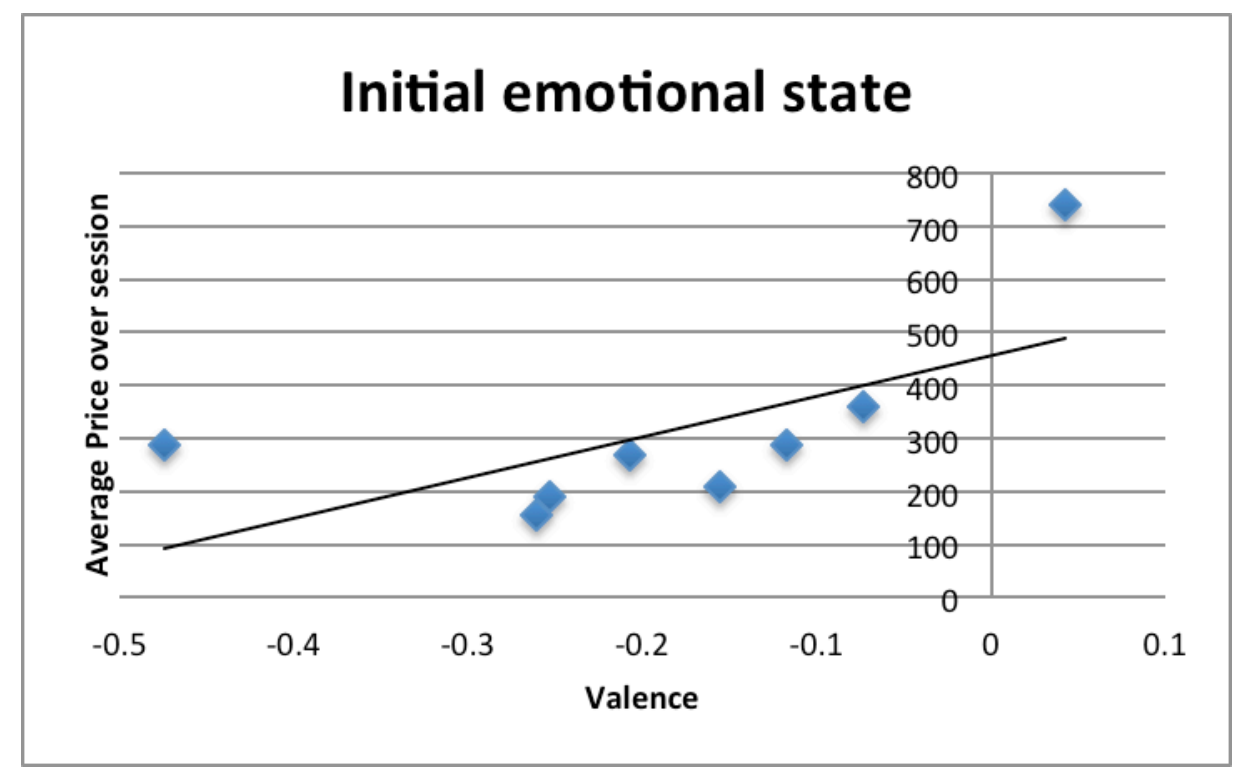

Average over 30 seconds prior to period 1 market open. Each data point is average for one session. 
Figure 5: Fear Prior to Market Open and Price Level

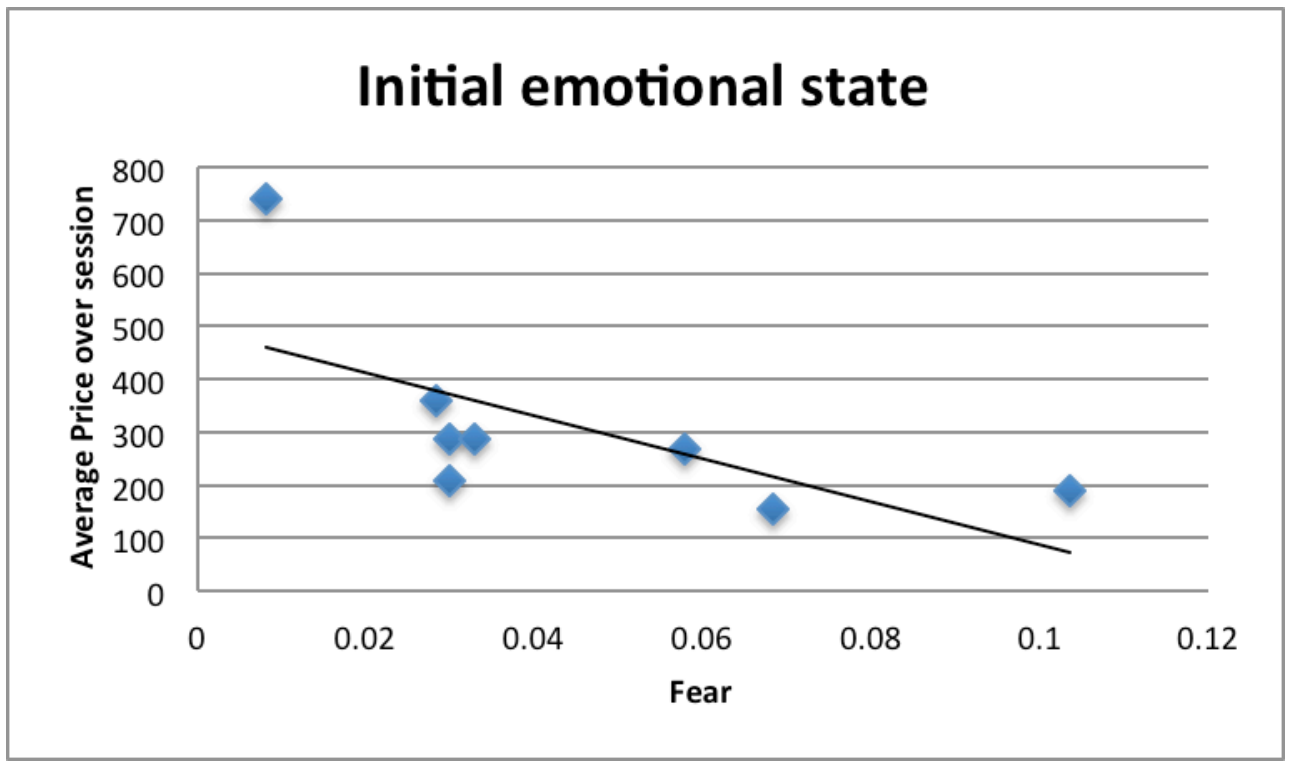

Average over 30 seconds prior to period 1 market open. Each data point is average for one session. 
Figure 6: The Relationship between Individual Emotional Variance and Net Purchases, Boom Period

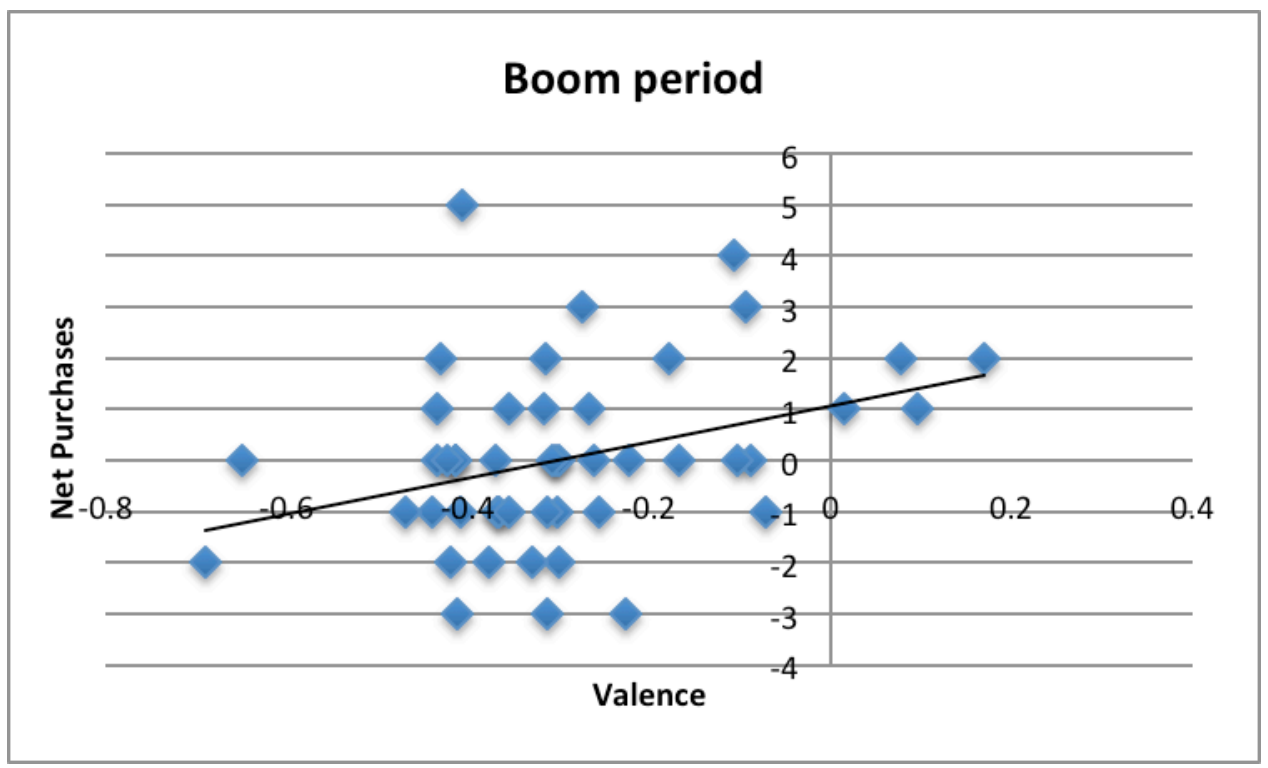

Each data point represents one individual. 
Figure 7: Relationship between Neutrality and Earnings, Crash Period

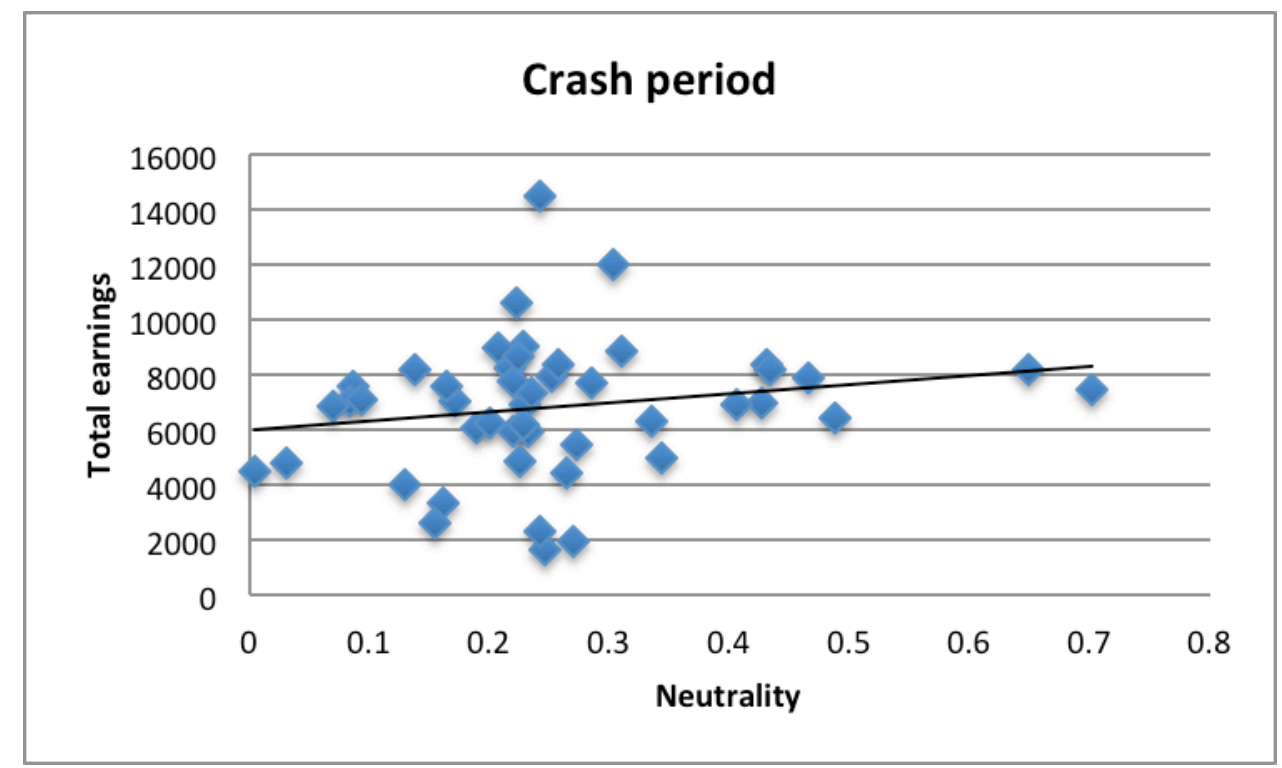

Each data point represents one individual. 


\section{APPENDIX I: Instructions for the Loss Aversion Measurement Task}

Welcome to this experiment. The instructions are simple and if you follow them carefully and make good decisions, you might earn a considerable amount of money, which will be paid to you by bank transfer at the end of the experiment.

The session will be divided in two parts and you will have the opportunity to earn money in both of them.

\section{Part I}

In the first part of the experiment six bets will be presented to you. Each bet gives you a 50-50 chance of winning some money or losing some money.

For each bet, you must decide if you want to play it or not, although only one randomly chosen decision will count toward your earnings.

After all participants have made their decisions for each of the six bets, the experimenter will roll a six-sided die. The outcome of the roll will determine the one single bet that will count to determine your earnings. If the die reads 1 , you will be paid for your decision in the first lottery. If the die reads 2 , you will be paid for your decision in the second lottery, and so on. Exactly one of the six bets will count.

After the die is rolled, if you decided not to play the bet chosen by the die roll, your earnings will be 0 euros for this part of the experiment.

If you decided to play that bet chosen by the die roll, there will be a 50-50 chance for you to win or lose the amount of money indicated in the bet. Then, the experimenter will toss a coin for each participant. If the coin comes up heads you lose and if the coin comes up tails you win the amount of money specified in the lottery.

\section{Lottery (50-50 chance)}

Lose $0.5 €$ or win $4.5 €$

Lose $1.5 €$ or win $4.5 €$

Lose $2.5 €$ or win $4.5 €$

Lose $3.5 €$ or win $4.5 €$

Lose $4.5 €$ or win $4.5 €$

Lose $5.5 €$ or win $4.5 €$

\section{Accept to play?}

$\begin{array}{ccccc}\circ & \text { Yes } & & \circ & \text { No } \\ \circ & \text { Yes } & & \circ & \text { No } \\ \circ & \text { Yes } & & \circ & \text { No } \\ \circ & \text { Yes } & & \circ & \text { No } \\ \circ & \text { Yes } & & \circ & \text { No } \\ \circ & \text { Yes } & & \circ & \text { No }\end{array}$




\section{APPENDIX II: Instructions for the Asset Market}

1. General Instructions

The second part of the experiment consists of a sequence of trading Periods in which you will have the opportunity to buy and sell in a market. The currency used in the market is ECU. All trading will be done in terms of ECU. The final payment to you at the end of the experiment will be in euros. The conversion rate is: $\mathbf{5 0 0}$ ECU to 1 euro.

2. How to use the computerized market

In the top right hand corner of the screen you see how much time is left in the current trading Period. The goods that can be bought and sold in the market are called Shares. On the left side of your screen you see the number of Shares you currently have and the amount of Money you have available to buy Shares.

If you would like to offer to sell a share, use the text area entitled "Enter offer to sell" in the first column. In that text area you can enter the price at which you are offering to sell a share, and then select "Submit Offer To Sell". Please do so now. Type in a number in the appropriate space, and then click on the field labeled "Submit Offer To Sell". You will notice that nine numbers, one submitted by each participant, now appear in the second column from the left, entitled "Offers To Sell". Your offer is listed in blue. Submitting a second offer will replace your previous offer.

The lowest offer-to-sell price will always be on the bottom of that list. You can select an offer by clicking on it. It will then be highlighted. If you select "Buy", the button at the bottom of this column, you will buy one share for the currently selected sell price. Please purchase a share now by selecting an offer and clicking the "Buy" button. Since each of you had offered to sell a share and attempted to buy a share, if all were successful, you all have the same number of shares you started out with. This is because you bought one share and sold one share. Please note that if you have an offer selected and the offer gets changed, it will become deselected if the offer became worse for you. If the offer gets better, it will remain selected.

When you buy a share, your Money decreases by the price of the purchase. When you sell a share your Money increases by the price of the sale. You may make an offer to buy a unit by selecting "Submit offer to buy." Please do so now. Type a number in the text area "Enter offer to buy", then press the red button labeled "Submit Offer To Buy". You can replace your offer-to-buy by submitting 
a new offer. You can accept any of the offers-to-buy by selecting the offer and then clicking on the "Sell" button. Please do so now.

In the middle column, labeled "Transaction Prices", you can see the prices at which Shares have been bought and sold in this period. You will now have about 5 minutes to buy and sell shares. This is a practice period. Your actions in the practice period do not count toward your earnings and do not influence your position later in the experiment. The only goal of the practice period is to master the use of the interface. Please be sure that you have successfully submitted offers to buy and offers to sell. Also be sure that you have accepted buy and sell offers. If you have any questions, please raise your hand and the experimenter will come by and assist you.

3. Specific Instructions for this experiment

The experiment will consist of 15 trading periods. In each period, there will be a market open for 2 minutes, in which you may buy and sell shares. Shares are assets with a life of 15 periods, and your inventory of shares carries over from one trading period to the next. You may receive dividends for each share in your inventory at the end of each of the 15 trading periods.

At the end of each trading period, including period 15, the computer will randomly determine the dividend value for all shares in that period. Each period, each share you hold at the end of the period:

\author{
earns you a dividend of 0 ECU with a $1 / 4$ chance \\ earns you a dividend of 8 ECU with a $1 / 4$ chance \\ earns you a dividend of 28 ECU with a $1 / 4$ chance \\ earns you a dividend of $60 \mathrm{ECU}$ with a $1 / 4$ chance
}

Each of the four dividend values is equally likely, thus the average dividend in each period is 24 . Dividends are added to your cash balance automatically.

After the dividend is paid at the end of period 15, there will be no further earnings possible from shares. 


\section{Average Holding Value Table}

You can use your AVERAGE HOLDING VALUE TABLE to help you make decisions. There are 5 columns in the table. The first column, labeled Ending Period, indicates the last trading period of the experiment. The second column, labeled Current Period, indicates the period during which the average holding value is being calculated. The third column gives the number of holding periods from the period in the second column until the end of the experiment. The fourth column, labeled Average Dividend per Period, gives the average amount that the dividend will be in each period for each unit held in your inventory. The fifth column, labeled Average Holding Value Per Unit of Inventory, gives the average value for each unit held in your inventory from now until the end of the experiment. That is, for each share you hold for the remainder of the experiment, you will earn on average the amount listed in column 5 .

Suppose for example that there are 7 periods remaining. Since the dividend on a Share has a $25 \%$ chance of being 0 , a $25 \%$ chance of being 8 , a $25 \%$ chance of being 28 and a $25 \%$ chance of being 60 in any period, the dividend is on average 24 per period for each Share. If you hold a Share for the remaining 7 periods, the total dividend for the Share over the 7 periods is on average $7 * 24=168$. Therefore, the total value of holding a Share over the 7 periods is on average 168

\section{AVERAGE HOLDING VALUE TABLE}

\begin{tabular}{|c|c|c|c|l|}
\hline Ending Period & Curent Period & $\begin{array}{c}\text { Number of } \\
\text { Remaining } \\
\text { Periods }\end{array}$ & $\begin{array}{c}\text { Average } \\
\text { Dividend per } \\
\text { Period }\end{array}$ & $\begin{array}{c}\text { Average Holding } \\
\text { Value per Unit of } \\
\text { Inventory }\end{array}$ \\
\hline 15 & 1 & 15 & 24 & $15 \times 24=360$ \\
\hline 15 & 3 & 14 & 24 & $14 \times 24=336$ \\
\hline 15 & 4 & 13 & 24 & $13 \times 24=312$ \\
\hline 15 & 5 & 12 & 24 & $12 \times 24=288$ \\
\hline 15 & 6 & 11 & 24 & $11 \times 24=264$ \\
\hline 15 & 7 & 10 & 24 & $10 \times 24=240$ \\
\hline 15 & 8 & 9 & 24 & $9 \times 24=216$ \\
\hline 15 & 9 & 8 & 24 & $8 \times 24=192$ \\
\hline 15 & 10 & 7 & 24 & $7 \times 24=168$ \\
\hline 15 & 11 & 6 & 24 & $6 \times 24=144$ \\
\hline 15 & 12 & 5 & 24 & $5 \times 24=120$ \\
\hline 15 & 13 & 4 & 24 & $4 \times 24=96$ \\
\hline 15 & 14 & 3 & 24 & $3 \times 24=72$ \\
\hline 15 & 15 & 2 & 24 & $2 \times 24=48$ \\
\hline 15 & & 1 & 24 & $1 \times 24=24$ \\
\hline
\end{tabular}




\section{Your Earnings}

Your earnings for this part of the experiment will equal the amount of cash that you have at the end of period 15, after the last dividend has been paid. The amount of cash you will have is equal to:

The cash (called "Money" on your screen) you have at the beginning of the experiment

+ dividends you receive

+ money received from sales of shares

- money spent on purchases of shares 